\title{
VDR rs2228570 Polymorphism Is Related to Non-Progression to AIDS in Antiretroviral Therapy Naïve HIV-Infected Patients
}

\author{
María A. Jiménez-Sousa ${ }^{1, *}$, José Luis Jiménez ${ }^{2,3}$, Amanda Fernández-Rodríguez ${ }^{1}$ (D), \\ Oscar Brochado-Kith ${ }^{1}$, José María Bellón ${ }^{3}{ }^{\mathbb{D}}$, Félix Gutierrez ${ }^{4,+}{ }^{+}$, Cristina Díez ${ }^{5, \ddagger}$, \\ Enrique Bernal-Morell ${ }^{6, \ddagger(\mathbb{D})}$, Pompeyo Viciana ${ }^{7, \ddagger}$, María A. Muñoz-Fernández ${ }^{8,9}$ and \\ Salvador Resino 1,*iD
}

1 Unidad de Infección Viral e Inmunidad, Centro Nacional de Microbiología, Instituto de Salud Carlos III, Carretera Majadahonda-Pozuelo, Km 2.2, 28220 Madrid, Spain; amandafr@isciii.es (A.F.-R.); brochado1993@gmail.com (O.B.-K.)

2 Plataforma de Laboratorio, Hospital General Universitario “Gregorio Marañón”, 28007 Madrid, Spain; joseluis.jimenez@salud.madrid.org

3 Fundación para la Investigación Biomédica, Hospital General Universitario Gregorio Marañón, Instituto de Investigación Sanitaria Gregorio Marañón (IiSGM), 28007 Madrid, Spain; bellon23@gmail.com

4 Unidad de Enfermedades Infecciosas, Hospital General de Elche \& Universidad Miguel Hernández, 03202 Alicante, Spain; gutierrezfel@gmail.com

5 Servicio Microbiología, Unidad de Enfermedades Infecciosas/VIH, Hospital General Universitario Gregorio Marañon, 28007 Madrid, Spain; crispu82@gmail.com

6 Servicio de Enfermedades Infecciosas, Hospital General Universitario Reina Sofia, 30003 Madrid, Spain; ebm.hgurs@gmail.com

7 Servicio de Enfermedades Infecciosas, Hospital Virgen del Rocío, 41013 Seville, Spain; pompeyo.viciana.sspa@juntadeandalucia.es

8 Sección Inmunología, Laboratorio Inmuno Biología Molecular, Hospital General Universitario Gregorio Marañón, IiSGM, and Spanish HIV HGM BioBank, 28007 Madrid, Spain; mmunoz.hgugm@gmail.com

9 Networking Research Center on Bioengineering, Biomaterials and Nanomedicine (CIBER-BBN), 28007 Madrid, Spain

* Correspondence: jimenezsousa@isciii.es (M.A.J.-S.); sresino@isciii.es (S.R.); Tel.: +34-918-223-266 (M.A.J.-S. \& S.R.); Fax: +34-918-223-269 (M.A.J.-S. \& S.R.)

+ On behalf of CoRIS and the Spanish HIV HGM BioBank integrated into the Spanish AIDS Research Network (Appendix A).

$\ddagger$ On behalf of LTNPs Cohort integrated into the Spanish AIDS Research Network (Appendix B).

Received: 8 February 2019; Accepted: 26 February 2019; Published: 5 March 2019

check for updates

\begin{abstract}
Background: Vitamin D is a fundamental regulator of host defenses by activating genes related to innate and adaptive immunity. In this study, we analyzed the association among single nucleotide polymorphisms (SNPs) in the vitamin D receptor (VDR) gene, with clinical patterns of AIDS progression in antiretroviral treatment (ART)-naïve HIV-infected patients. Methods: We conducted a retrospective study in $667 \mathrm{HIV}$-infected patients, who were classified within three groups according to their AIDS progression pattern (183 long-term non-progressors (LTNPs), 334 moderate progressors (MPs), and 150 rapid progressors (RPs)). Five VDR SNPs (rs11568820, rs4516035, rs2228570, rs1544410, and rs7975232) were genotyped using Agena Bioscience's MassARRAY platform. Results: Significant association results were found for rs2228570. Within all HIV patients, the presence of $\mathrm{T}$ allele at VDR rs2228570 SNP was protective against AIDS progression (ordinal outcome) under additive (adjusted odds ratio $(\mathrm{aOR})=0.75 ; p=0.009)$, dominant $(\mathrm{aOR}=0.69 ; p=0.015)$, and codominant $(\mathrm{aOR}$ $=0.56 ; p=0.017)$ inheritance models. In addition, the same allele was protective under additive and codominant inheritance models when we compared with LTNPs vs. RPs [aOR $=0.64(p=0.019)$ and $\mathrm{aOR}=0.37(p=0.018)$, respectively] and when we compared MPs vs. $\operatorname{RPs}[\mathrm{aOR}=0.72(p=0.035)$ and $\mathrm{aOR}=0.45(p=0.028)$, respectively]. Conclusions: The $V D R$ rs2228570 T allele was related
\end{abstract}


to a lower AIDS progression pattern in ART-naïve HIV-infected patients. These findings expand upon the knowledge about HIV pathogenesis in untreated HIV-infected patients with different clinical outcomes.

Keywords: single nucleotide polymorphisms; VDR; LTNPs; AIDS; non-progression

\section{Introduction}

The natural history of human immunodeficiency virus (HIV) infection has a substantial inter-individual variability on the progression of acquired immunodeficiency syndrome (AIDS) among antiretroviral treatment (ART)-naïve, HIV-infected patients [1]. Three major patterns can be identified according to the AIDS progression rate: Long-term non-progressors (LTNPs), moderate progressors (MPs), and rapid progressors (RPs) [2,3]. LTNPs are patients who do not progress to AIDS over an extended period, and they have a total or partial control of HIV replication, high CD4+ lymphocyte numbers, and absence of clinical symptoms. MPs (also known as moderate, intermediate or typical progressors) in opposition to the extremes of the clinical-immunological distribution (LTNPs and RP), are patients without viremia control, who slowly progress to AIDS during an extended period after seroconversion (3 to 10 years after seroconversion). RPs are patients who rapidly progress to AIDS within the first year after seroconversion. This inter-individual variability to AIDS progression is probably the result of a complex interaction between genetic background, immune system, and viral factors $[4,5]$.

Vitamin D (VitD) deficiency is related to osteomalacia, rickets, and non-skeletal diseases, such as infectious diseases [6]. VitD triggers effective anti-microbial pathways against bacterial, fungal, and viral pathogens in host cells, by activating genes that enhance innate and adaptive immunity [7]. Thus, VitD deficiency has been related to a higher incidence and severity of Mycobacterium tuberculosis, $\mathrm{HIV}$, and hepatitis $\mathrm{C}$ virus (HCV) infection [8,9]. Regarding HIV infection, VitD deficiency is present in $70-85 \%$ of patients infected with HIV, and may be related to non-HIV-related risk factors (gender, advanced age, limited sunlight exposure, genetic background, among others) and HIV-related factors (HIV infection itself, ART, and higher incidence of malnutrition and comorbidities, among others) [9,10]. High levels of VitD seem to provide a natural resistance to HIV infection, whereas low levels of VitD are related to a higher values of HIV viral load in plasma, inflammation, immune activation, decrease of CD4+ T-cells and rapid AIDS progression [7]. Moreover, VitD levels are related to CD4+ T-cell recovery after 24 weeks of VitD supplementation, whereas VitD deficiency is associated with impaired CD4+ T-cell count recovery in HIV-positive patients on ART [7].

VitD effects are mediated by its nuclear receptor, vitamin D receptor (VDR), which acts as a transcription factor that promotes the expression of vitamin D-related genes [11]. Additionally, VitD may bind to an external VDR, which is located on the cell membrane (VDRm), and to promote the secretion of growth factors and cytokines through the modulation of nuclear transcription factors [7]. The VDR gene is located at human chromosome 12q13, the VDR region is organized in three main haplotype blocks (A, B and C) and several sub-blocks, which vary in size and distributions among European, African, and Asian populations [12,13]. Some of the most studied single nucleotide polymorphisms (SNPs) have been Bsm1 (rs1544410) and ApaI (rs7975232), located at block B; GATA (rs4516035) and Cdx2 (rs11568820) located at block C2, and the Fok1 (rs2228570), located at exon 2 between blocks B and C. Several single nucleotide polymorphisms (SNPs) at the VDR gene have been associated with non-skeletal health problems, especially infectious and auto-immune related diseases [14]. There is scarce information about VDR SNPs on the progression to AIDS in naïve HIV-infected patients [15-18], and these studies were performed with lower sample sizes. Thus, since $V D R$ SNPs have been associated with a large number of immune-mediated diseases, we hypothesized 
that these SNPs could play an important role in the clinical progression of HIV-infected patients, and could be associated with clinical patterns of AIDS progression.

\section{Objective}

We aimed to analyze the association among five VDR SNPs and the clinical patterns of progression, categorized as LTNPs, MPs, and RPs, for the natural history of HIV infection in European ART-naïve HIV-infected patients from two large Spanish cohorts (Cohort of the Spanish AIDS Research Network (CoRIS) and Cohort of LTNPs).

\section{Patients and Methods}

\subsection{Patients}

We conducted a retrospective study in 667 European ART-naïve HIV-infected patients from both CoRIS and LTNPs cohorts, whose samples were available at the Spanish HIV HGM Biobank [19]. The methodological and organizational aspects, and the characteristics of the subjects enrolled in the present study, have been previously described [20]. Moreover, 113 healthy blood donors (HIV, HCV, and HBV negative subjects) from "Centro de Transfusión de la Comunidad de Madrid" were used as a Control-group. The programs were approved by the institutional review boards of each participating center. In addition, the Research Ethics Committee of the Instituto de Salud Carlos III (ISCIII) approved this study (CEI PI_2010-v3), which was conducted under the ethical principles of the Declaration of Helsinki. All patients signed an informed consent form.

Patients infected with HIV were classified within three groups depending on their drop in CD4 T-cell counts and AIDS disease progression rates in the absence of ART [21,22]: (a) 183 LTNPs, who had asymptomatic HIV infection over ten years after seroconversion, and always showing CD4+ $\geq 500$ cells $/ \mathrm{mm}^{3}$ and RNA-viral load $\leq 10,000$ copies/mL. (b) 334 MPs who had an average decrease of 50-100 CD4+ $/ \mathrm{mm}^{3}$ per year for at least two years after HIV diagnosis. (c) $150 \mathrm{RPs}$, who had two or more CD4+ T-cell values below $350 / \mathrm{mm}^{3}$ (recommended threshold for initiating ART) and/or who had AIDS or AIDS-related death within three years after HIV seroconversion (seroincidents). These are three well-defined groups with available sample in the Spanish HIV Biobank, which show the three main patterns of progression to AIDS. All patients had a regular follow up of CD4+ counts and plasma HIV-RNA during the study period.

\subsection{DNA Genotyping}

We selected five VDR SNPs, which had been previously related to the risk of acquisition and progression of HIV infection [16-18,23,24]. These SNPs are located upstream (rs11568820 and rs4516035), within the coding region (rs2228570 [missense variant]), and at two intronic region (rs1544410 and rs7975232).

Samples from patients were kindly provided by the HIV BioBank integrated into the Spanish AIDS Research Network (RIS). The samples were immediately processed and frozen after their reception. The total DNA isolation was performed from peripheral blood mononuclear cells with Qiagen columns (QIAamp DNA Blood Midi/Maxi; Qiagen, Hilden, Germany). DNA genotyping was carried out at the Spanish National Genotyping Center (CeGen; http:/ / www.cegen.org/) by Agena Bioscience's MassARRAY platform (San Diego, CA, USA) with the iPLEX ${ }^{\circledR}$ Gold assay design system.

\subsection{Statistical Analysis}

For the descriptive study, categorical data and proportions were analyzed using the chi-squared test or Fisher's exact test. Kruskal-Wallis and Mann-Whitney U tests were used to compare continuous variables among independent groups. 
The genetic association analysis was carried out according to dominant, recessive, over-dominant, codominant, and additive models. The Mantel-Haenszel linear-by-linear association test (values between -1 and +1 ), a non-parametric test for measuring the association between ordinal data, was used to explore the distribution of $V D R$ genotypes among the three clinical patterns of AIDS progression. We also used Generalized Linear Models (GLMs) adjusted by age at HIV diagnosis, gender, and risk group (men who have sex with men (MSM) versus others). Firstly, a GLM model, with a multinomial distribution (cumlogit-link), was used to evaluate the association of VDR SNPs with the three clinical patterns of AIDS progression (ordinal variable: 0, LTNP; 1 , MP; 2, RP). The reference category was the LTNP-group. The goodness of fit of each model was evaluated by the Akaike information criterion (AIC) value and Bayesian information criterion (BIC). In order to exclude spurious associations, multiple testing correction was carried out by the false discovery rate (FDR) with the Benjamini and Hochberg procedure. Secondly, a GLM model with a binomial distribution (logit-link) was used for estimating frequency differences of VDR SNPs between clinical patterns of AIDS progression (dichotomous variable: LTNPs vs MPs; LTNPs versus RPs; MPs versus RPs). In this case, only SNPs with an adjusted p-value less than 0.05 (after an FDR correction) from the ordinal regression (Step 1) were analyzed. All statistical tests were performed with the Statistical Package for the Social Sciences (SPSS) 22.0 software (IBM Corp., Armonk, CA, USA). Statistical significance was defined as $p<0.05$. All $p$-values were two-tailed.

Haploview 4.2 software (MIT/Harvard Broad Institute, Cambridge, MA, USA) was used to determine the Hardy-Weinberg equilibrium (HWE) and pairwise linkage disequilibrium (LD), using the standardized $\mathrm{D}^{\prime}$ and $r^{2}$ values.

\section{Results}

\subsection{Characteristics of the Study Population}

Table 1 shows the epidemiological and clinical characteristics of HIV infected patients (183 LTNPs, $334 \mathrm{MPs}$, and $150 \mathrm{RPs})$. LTNP-patients had the highest values of age at the moment of HIV diagnosis, age at the study inclusion, percentage of intravenous drug users (IDU) $(p<0.001)$, and the lowest proportion of male patients $(p<0.001)$. Besides, MP and RP groups were diagnosed with HIV infection in the 2000s and had higher percentages of men and homosexual HIV transmission than LTNP group.

\subsection{Characteristics of VDR SNPS}

All VDR SNPs (rs11568820, rs1544410, rs2228570, rs4516035, and rs7975232) were in HWE $(p>0.05)$, the values for the minor allelic frequency (MAF) were higher than $5 \%$, and the genotyping call-rate success was over 95\% (Table 2). Similar values of genotypic frequencies for VDR SNPs were found in healthy-controls and HIV-infected patients (Table 2). Furthermore, the VDR genotype frequencies were in accordance with the NCBI SNP database (http:/ / www.ncbi.nlm.nih.gov/ projects / SNP). Moreover, LD values were very high for rs7975232 and rs1544410 $\left(\mathrm{D}^{\prime}=1.0\right)$, and rs11568820 and rs4516035 ( $\mathrm{D}^{\prime}=1.0$ ); but the $r^{2}$ statistic was very low among all VDR SNPs (Figure 1), which means that each SNP provides different information. 
Table 1. Clinical and epidemiological characteristics of HIV infected patients and healthy donors.

\begin{tabular}{|c|c|c|c|c|c|c|c|}
\hline \multirow{2}{*}{ Characteristics } & \multicolumn{3}{|c|}{ Controls vs. All HIV Patients } & \multicolumn{4}{|c|}{ HIV Groups of Patients } \\
\hline & Control & All HIV ${ }^{(*)}$ & $p$-Value ${ }^{(a)}$ & LTNPs & MPs & RPs & $p$-Value ${ }^{(b)}$ \\
\hline No. & 113 & 667 & & 183 & 334 & 150 & \\
\hline Male & $93(82.3 \%)$ & $540(81.4 \%)$ & 0.829 & $\begin{array}{c}115 \\
(64.2 \%)\end{array}$ & $\begin{array}{c}283 \\
(84.7 \%)\end{array}$ & $\begin{array}{c}142 \\
(94.7 \%)\end{array}$ & $<0.001$ \\
\hline Age (years) & $\begin{array}{c}42.0 \\
(37.0 ; 49.0)\end{array}$ & $\begin{array}{c}41.3 \\
(35.0 ; 48.4)\end{array}$ & 0.427 & $\begin{array}{c}48.7 \\
(46.0 ; 51.7)\end{array}$ & $\begin{array}{c}38.2 \\
(33.2 ; 45.3)\end{array}$ & $\begin{array}{c}38.3 \\
(33.0 ; 43.8)\end{array}$ & $<0.001$ \\
\hline $\begin{array}{l}\text { Age of HIV } \\
\text { diagnosis }\end{array}$ & - & $\begin{array}{c}34.3 \\
(29.0 ; 40.4)\end{array}$ & - & $\begin{array}{c}39.8 \\
(34.3 ; 43.7)\end{array}$ & $\begin{array}{c}31.8 \\
(27.0 ; 38.4)\end{array}$ & $\begin{array}{c}34.0 \\
(29.6 ; 38.1)\end{array}$ & $<0.001$ \\
\hline $\begin{array}{c}\text { Year of HIV } \\
\text { diagnosis }\end{array}$ & - & $\begin{array}{c}2006 \\
(1999 ; 2008)\end{array}$ & - & $\begin{array}{l}1993 \\
(1990 ; \\
1997)\end{array}$ & $\begin{array}{l}2006 \\
(2004 ; \\
2008)\end{array}$ & $\begin{array}{l}2009 \\
(2007 ; \\
2010)\end{array}$ & $<0.001$ \\
\hline HIV acquired & - & & - & & & & \\
\hline IDU & - & $166(25.0 \%)$ & - & $\begin{array}{c}130 \\
(72.6 \%)\end{array}$ & $29(8.7 \%)$ & $7(4.7 \%)$ & $<0.001$ \\
\hline Homosexual & - & $359(54.1 \%)$ & - & $13(7.3 \%)$ & $\begin{array}{c}220 \\
(65.9 \%)\end{array}$ & $\begin{array}{c}126 \\
(84.0 \%)\end{array}$ & \\
\hline Heterosexual & - & $118(17.8 \%)$ & - & $27(15.1 \%)$ & $76(22.8 \%)$ & $15(10.0 \%)$ & \\
\hline Others & - & $20(3.0 \%)$ & - & $9(5.0 \%)$ & $9(2.7 \%)$ & $2(1.3 \%)$ & \\
\hline
\end{tabular}

$p$-values were calculated by Chi-square, Mann-Whitney and Kruskal-Wallis tests: ${ }^{(a)}$ differences between control group and all HIV infected patients; ${ }^{(b)}$ differences among HIV groups. Statistically significant differences are shown in bold. ${ }^{(*)}$ Clinical and epidemiological data for three HIV-infected patients were not available. IDU, intravenous drug users; HIV, Human immunodeficiency virus; LTNPs, Long Term Non Progressors; MPs, Moderate Progressors; RPs, Rapid progressors.

Table 2. Characteristics of vitamin D receptor (VDR) polymorphisms in HIV infected patients and healthy donors.

\begin{tabular}{|c|c|c|c|c|c|c|c|}
\hline SNPs & HWE & & & HWE & & & $p$-Value \\
\hline \multirow{4}{*}{ rs11568820 } & & \multicolumn{2}{|c|}{$n=112$} & \multicolumn{4}{|c|}{$n=665$} \\
\hline & \multirow{3}{*}{0.616} & $\mathrm{CC}$ & $59.8 \%$ & 0.501 & $\mathrm{CC}$ & $57.0 \%$ & \multirow{3}{*}{0.800} \\
\hline & & $\mathrm{CT}$ & $33.9 \%$ & & $\mathrm{CT}$ & $35.3 \%$ & \\
\hline & & $\mathrm{TT}$ & $6.3 \%$ & & $\mathrm{TT}$ & $7.7 \%$ & \\
\hline \multirow{4}{*}{ rs1544410 } & & \multicolumn{2}{|c|}{$n=112$} & \multicolumn{4}{|c|}{$n=666$} \\
\hline & \multirow{3}{*}{0.233} & $\mathrm{CC}$ & $36.6 \%$ & 0.835 & $\mathrm{CC}$ & $37.1 \%$ & \multirow{3}{*}{0.477} \\
\hline & & $\mathrm{CT}$ & $42.9 \%$ & & $\mathrm{CT}$ & $46.8 \%$ & \\
\hline & & $\mathrm{TT}$ & $20.5 \%$ & & $\mathrm{TT}$ & $16.1 \%$ & \\
\hline \multirow{4}{*}{ rs2228570 } & & \multicolumn{2}{|c|}{$n=112$} & \multicolumn{4}{|c|}{$n=664$} \\
\hline & \multirow{3}{*}{0.474} & $\mathrm{CC}$ & $48.2 \%$ & \multirow[t]{3}{*}{0.812} & $\mathrm{CC}$ & $41.7 \%$ & \multirow{3}{*}{0.435} \\
\hline & & $\mathrm{CT}$ & $40.2 \%$ & & $\mathrm{CT}$ & $44.9 \%$ & \\
\hline & & $\mathrm{TT}$ & $11.6 \%$ & & $\mathrm{TT}$ & $13.4 \%$ & \\
\hline \multirow{4}{*}{ rs4516035 } & & \multicolumn{2}{|c|}{$n=113$} & \multicolumn{4}{|c|}{$n=666$} \\
\hline & \multirow{3}{*}{0.149} & $\mathrm{TT}$ & $40.7 \%$ & \multirow[t]{3}{*}{0.895} & $\mathrm{TT}$ & $40.4 \%$ & \multirow{3}{*}{0.202} \\
\hline & & $\mathrm{CT}$ & $40.7 \%$ & & $\mathrm{CT}$ & $46.8 \%$ & \\
\hline & & CC & $18.6 \%$ & & $\mathrm{CC}$ & $12.8 \%$ & \\
\hline \multirow{4}{*}{ rs7975232 } & & \multicolumn{2}{|c|}{$n=113$} & \multicolumn{4}{|c|}{$n=662$} \\
\hline & \multirow{3}{*}{0.294} & $\mathrm{AA}$ & $37.2 \%$ & \multirow[t]{3}{*}{0.862} & AA & $29.0 \%$ & \multirow{3}{*}{0.217} \\
\hline & & $\mathrm{AC}$ & $43.4 \%$ & & AC & $48.9 \%$ & \\
\hline & & $\mathrm{CC}$ & $19.5 \%$ & & CC & $22.1 \%$ & \\
\hline
\end{tabular}

p-values were calculated by Chi-squared test. VDR, vitamin D receptor; HWE, Hardy-Weinberg equilibrium; LTNPs, Long Term Non Progressors; MPs, Moderate Progressor; RPs, Rapid progressor. 


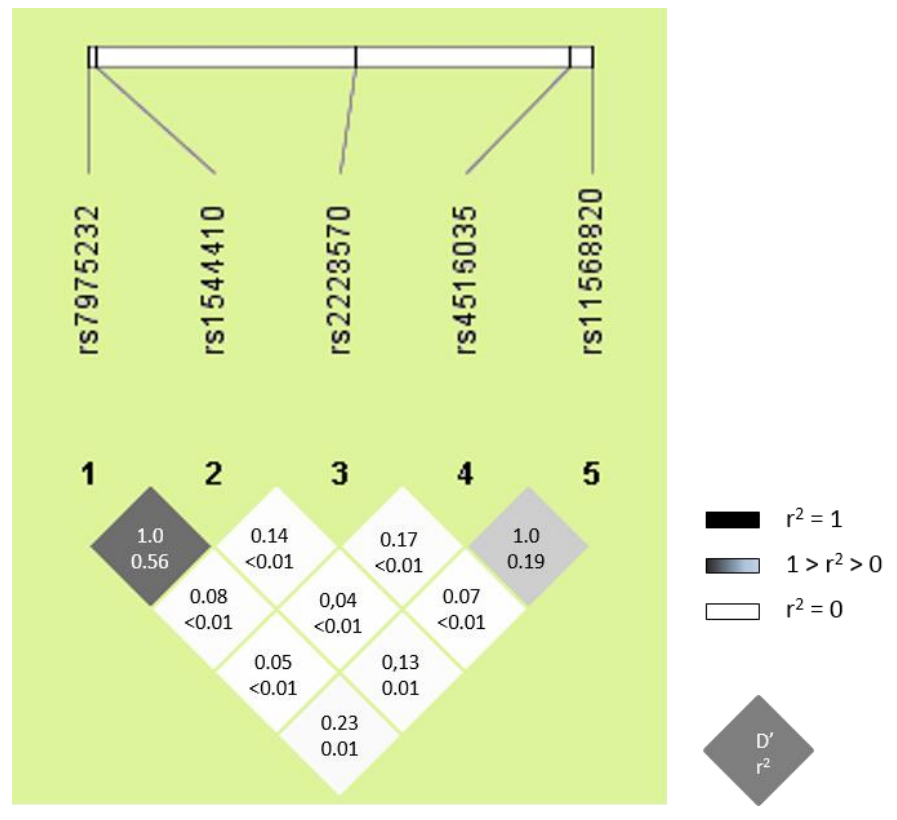

Figure 1. Pairwise linkage disequilibrium (LD) pattern for $V D R$ polymorphisms. The locations of each tested SNP, along the genome region, is indicated on top. Each diagonal represents a different SNP, with each square representing a pairwise comparison between two SNPs. The number in each square indicates the magnitude of LD, expressed as $\mathrm{D}^{\prime}$ and $r^{2}$. Color scheme: Grey color intensity decreases with decreasing $R$-squared value. Dark grey indicates strong LD; squares in light grey indicates weaker LD; white indicates very weak or no LD.

\subsection{VDR SNPs and AIDS Progression}

We explored the genetic association between VDR SNPs (rs11568820, rs1544410, rs2228570, rs4516035, and rs7975232) and the three clinical patterns of AIDS progression (LTNP, MP, and RP) by univariate analysis (Figure 2). We found a significant association for only rs2228570 SNP under an additive $(p=0.010)$, dominant $(p=0.031)$, recessive $(p=0.040)$, and codominant $(p=0.014)$ inheritance models. However, after the FDR (Benjamini \& Hochberg) controlling procedure, no significant $p$-values were obtained. Despite this, we do not necessarily think that this association between VDR rs2228570 SNP, and the clinical patterns of AIDS progression, could be a false positive. Correcting for multiple testing is generally a very strict methodology to maintain the statistical significance for certain SNPs that could be associated with the outcome variable. Furthermore, we also observed that the distribution of patients in each of the three categories of progression to AIDS, according to genotypes, showed a prominent "effect size" of the T allele for rs2228570.

Afterwards, the GLM tests adjusted for age, gender, and risk category largely confirmed these findings (Figure 3). Therefore, when analyzing all $667 \mathrm{HIV}$ patients, the presence of $\mathrm{T}$ allele at VDR rs2228570 SNP protected against AIDS progression (ordinal outcome) under additive (adjusted odds ratio $(\mathrm{aOR})=0.75 ; p=0.009)$, dominant $(\mathrm{aOR}=0.69 ; p=0.015)$, and codominant $(\mathrm{aOR}=0.56 ; p=0.017)$ inheritance models. In this case, $p$-values were also corrected by multiple comparison (FDR -Benjamini \& Hochberg), and remained significant. 


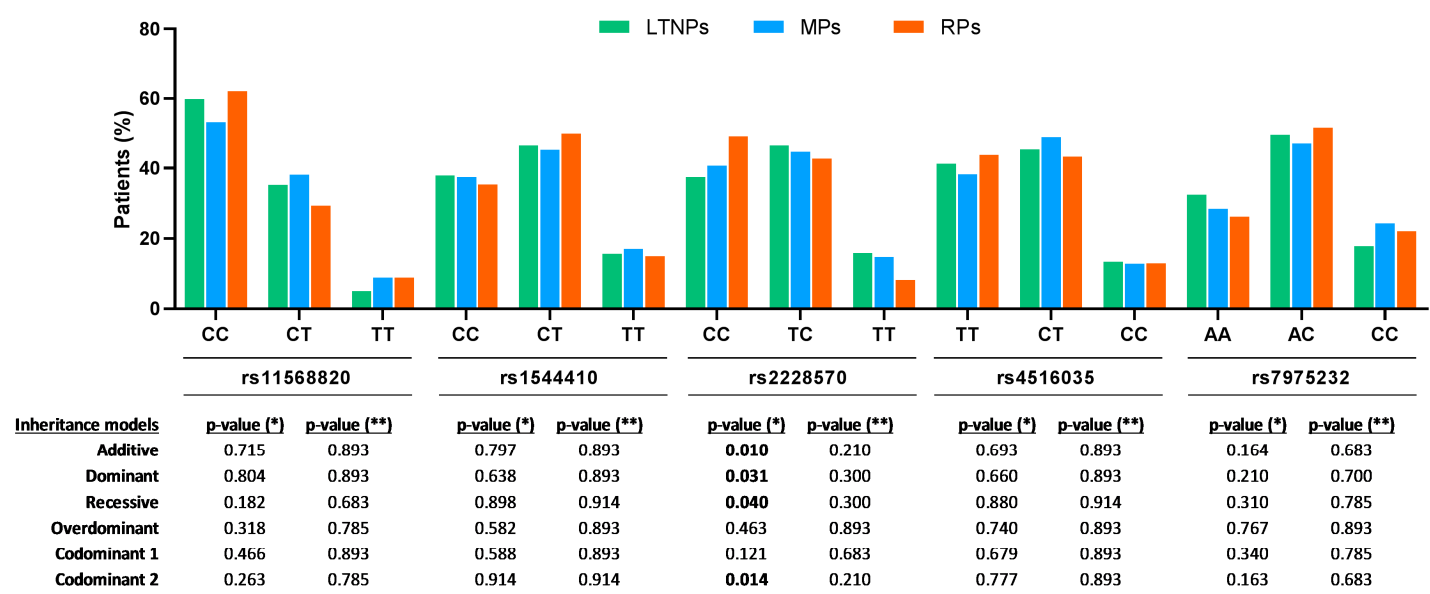

Figure 2. Genetic association of $V D R$ polymorphisms, with distinct patterns of AIDS progression in HIV infected patients. $p$-values were calculated by the Mantel-Haenszel linear-by-linear association test. $\left({ }^{*}\right)$, raw $p$-values; $\left({ }^{* *}\right), p$-values corrected for multiple testing using the false discovery rate (FDR) with Benjamini and Hochberg procedure ( $n=30$, multiple comparisons). VDR, vitamin D receptor; LTNPs, Long Term Non Progressors; MPs, Moderate Progressor; RPs, Rapid Progressor; Codominant 1 , homozygous more frequent versus heterozygous; Codominant 2 , more frequent homozygote versus less frequent homozygote.

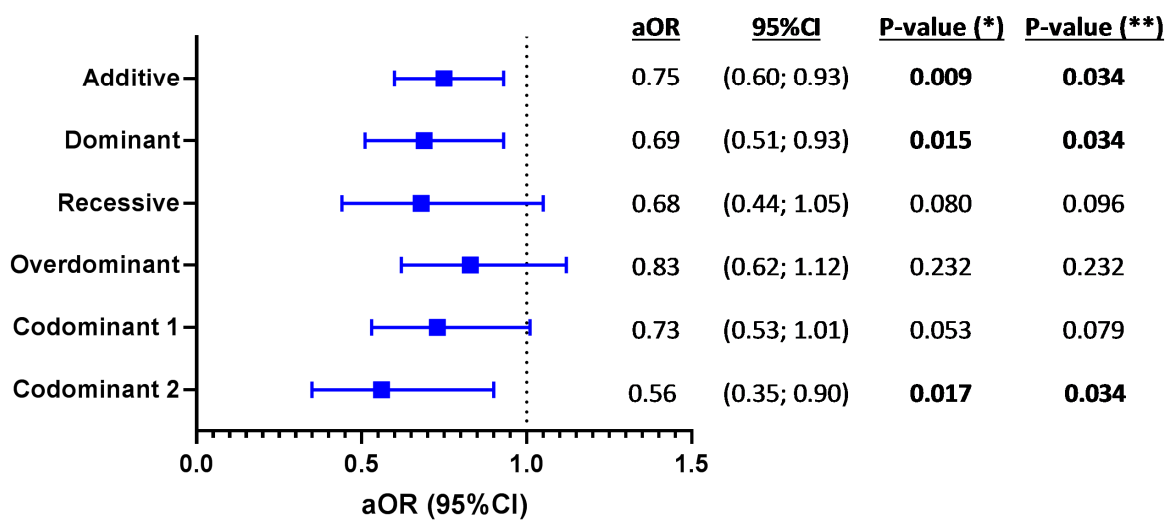

Figure 3. Genetic association of VDR rs2228570 polymorphisms with patterns of AIDS progression (ordinal variable) in HIV infected patients. $p$-values were calculated by ordinal regression adjusted for age, gender, and risk category (men who have sex with men (MSM) versus others). $\left.{ }^{*}\right)$, raw $p$-values; $(* *), p$-values corrected for multiple testing using the false discovery rate (FDR) with Benjamini and Hochberg procedure ( $n=6$, multiple comparisons). VDR, vitamin D receptor; LTNPs, Long Term Non Progressors; MPs, Moderate Progressor; RPs, Rapid Progressor; Codominant 1, codominant 1 refers to heterozygous genotype vs more frequent homozygous (genotype 1); Codominant 2, codominant 2 refers to less frequent homozygote (genotype 2) vs more frequent homozygote (genotype 1).

\section{Discussion}

In this study, we evaluated the distribution of VDR SNPs (rs11568820, rs1544410, rs2228570, rs4516035, and rs7975232) among European ART-naïve HIV-infected patients, from two large Spanish cohorts (CoRIS and LTNPs cohorts), grouped by their clinical progression pattern (LTNPs, MPs, RPs). Our most significant finding was that, HIV-infected patients carrying the VDR rs2228570 T allele, had lower odds of progression to AIDS.

VitD induces an antiviral effect in the body, that promotes the expression of antiviral genes, reduces the expression of CCR5 on CD4+ T-cells, promotes an HIV-1-restrictive CD38+HLA-DR+ phenotype, and reduces the ability of TNF $\alpha$ to upregulate HIV replication in latently infected CD4+ T-cells $[25,26]$. The variability that the genetic background of patients may confer differential 
susceptibility to HIV infection and progression to AIDS [5]. The five VDR SNPs analyzed in our study (rs11568820, rs1544410, rs2228570, rs4516035, and rs7975232) were previously involved in protection against HIV infection $[18,23,24]$. Four of them (rs11568820, rs1544410, rs2228570, and rs4516035) have been related to the AIDS progression in Spanish and Indian cohorts [15-18]. However, we have only confirmed the significant association of rs2228570 with AIDS progression, in accordance with the findings of Nieto et al. [17] and Laplana et al. [16]. In contrast, Barber et al. [15] and Torres et al. [18] did not analyze the VDR rs2228570 SNP. Therefore, rs2228570 polymorphism seem to have a relevant impact in the natural history of our ART-naïve HIV-infected patients, although we should not rule out that other SNPs in high LD, with rs2228570, could be the causal polymorphism.

Previous retrospective studies in very similar populations $[16,17]$ found a weak association in the VDR rs2228570 polymorphism. Our data has the key advantage of a much larger sample size and confirms the locus, although the most significant associations came from a slightly different genetic model. We therefore believe that the VDR rs2228570 polymorphism might be relevant for HIV progression, although the exact model (additive, recessive, dominant, over-dominant or codominant) remains to be determined. Even without a specific model, this study warrants further investigation on the potential role of $V D R$ SNPs, and this one in particular as a partial determinant of HIV progression.

The rs2228570 C->T polymorphism (also called FokI because may be detected by Restriction Fragment Length Polymorphism (RFLP) using the endonuclease FokI is located in the $5^{\prime}$ untranslated region (UTR), three codons before the start codon (ATG) $[27,28]$. Thus, the $C$ allele (F variant) does not originate any new start codon (ATG), whereas the T allele (f variant) creates a new start codon and a VDR protein, with three extra amino acids [28]. However, discrepant results have been published around the putative implication of rs2228570 polymorphism on the VDR expression and vitamin D signaling pathway. On the one hand, the $T$ allele has been related to a less efficient interaction between VDR protein and transcription factor IIB (TFIIB) [29], and to a lower VDR mRNA copy number [30]. This might be due to the three extra amino acids of the final protein, which could be disrupting a correct interaction. On the other hand, Oskooei et al. [31] described that the TT genotype was associated with a higher $V D R$ expression levels in breast cancer patients. Additionally, there are also studies that have described a lack of association between the VDR rs2228570 polymorphism and VDR expression in immune cells of European, and South African Populations [32,33], respectively. We did not analyze the effect of rs2228570 SNP at the functional level. However, we hypothesize that the effect of the T allele might cause a decrease in the level of expression of $V D R$ and the impairment of its function, which would induce the inhibition of HIV replication and block the destruction of CD4+ T cells.

\section{Limitations of the Study}

Firstly, this work is a retrospective study that included three groups of patients (defined by changes in CD4 T-cell counts and AIDS disease progression rates) with substantial differences in demographic and clinical characteristics. Thus, LTNPs acquired the HIV infection, mainly by IDU, and were diagnosed at the beginning of the 90s; while MPs and RPs were mainly MSM that were diagnosed of HIV infection more recently (2000s), these patients were predominantly men, with a younger age at the time of HIV diagnosis. These differences could introduce some bias in the study. Besides, the sample size was limited in some sub-groups of patients, which may influence the statistical significance level when the effects of the variables studied are not significant.

Secondly, our study was completely performed in Spanish Caucasians individuals. Thus, since the frequency of the alleles varies among races, an independent study with different ethnic groups would be interesting in clarifying the association between different genetic backgrounds. We should not rule out the influence of other factors, such as the exposure to sunlight, since vitamin D levels depend on the conversion rate of pro-vitamin D3 to pre-vitamin D3 by sunlight, which is affected by seasonal characteristics, latitude, radiation, and urban living. In our study, HIV-infected patients came from all different regions of Spain. 
Thirdly, the HCV coinfection data were available for $75 \%$ (500/677) of patients, but the data of HBV coinfection, opportunistic infections, and other non-AIDS-related co-morbidities (e.g., cancer, liver disease, renal impairment, diabetes, obesity, endocrine disease, and cardiovascular disease) were not available. Thus, these co-factors could not be included in the multivariate analysis to account for these effects.

\section{Conclusions}

In conclusion, the VDR rs2228570 T allele was related to a lower AIDS progression rate in European ART-naïve HIV-infected patients. These findings expand the knowledge about HIV pathogenesis in untreated HIV-infected patients with different clinical outcomes.

Author Contributions: Conceptualization, M.A.J.-S. and S.R.; Data curation, F.G., C.D., E.B.-M., P.V., and J.L.J.; formal analysis, M.A.J.-S., O.B.-K., J.M.B., and S.R.; funding acquisition, M.A.M.-F. and S.R.; investigation and methodology, M.A.J.-S., and J.L.J.; project administration, J.L.J. and S.R.; supervision and visualization, S.R.; writing-original draft preparation, M.A.J.-S. and S.R.; writing-review and editing: A.F.-R. and M.A.M.-F. All authors read and approved the final manuscript.

Funding: This work has been (partially) funded by the RD16/0025/0019 and RD16CIII/0002/0002, projects as part of Acción Estratégica en Salud, Plan Nacional de Investigación Científica, Desarrollo e Innovación Tecnológica (2013-2016) and cofinanced by Instituto de Salud Carlos III (Subdirección General de Evaluación) and Fondo Europeo de Desarrollo Regional (FEDER), RETIC PT17/0015/0042, Fondo de Investigación Sanitaria (FIS) (grant number PI16/01863, PI17/01115, PI17CIII/00003), EPIICAL Project and Comunidad de Madrid B2017/BMD-3703. Programa de Investigación de la Consejería de Sanidad de la Comunidad de Madrid to JLJ. CIBER-BBN is an initiative funded by the VI National R\&D\&i Plan 2008-2011, Iniciativa Ingenio 2010, the Consolider Program, and CIBER Actions and financed by the Instituto de Salud Carlos III with assistance from the European Regional Development Fund. COST CA17140 Cancer Nanomedicine-Front the Bench to Bebside. AFR are supported and funded by "Instituto de Salud Carlos III" [grant number CP14/0010].

Acknowledgments: The authors thank the Spanish National Genotyping Center (CEGEN PRB2-ISCIII) for providing SNP genotyping services (http://www.cegen.org). CEGEN is supported by grant PT13/0001, ISCIII-SGEFI/FEDER. We also acknowledge the patients in this study for their participation and the Centro de Transfusión of Comunidad de Madrid for the healthy donor blood samples provided. This study would not have been possible without the collaboration of all the patients, medical and nursery staff, and data managers who have taken part in the project. We want to particularly acknowledge the support of the HIV BioBank, which is integrated in the Spanish AIDS Research Network and all collaborating Centres for their generous contribution with clinical samples for the present work (see Appendices A and B). The HIV BioBank, is supported by Instituto de Salud Carlos III, Spanish Health Ministry (Grant $n^{\circ}$ RD06/0006/0035, RD12/0017/0037 and RD16/0025/0019) as part of the Plan Nacional R + D + I and cofinanced by ISCIII- Subdirección General de Evaluación y el Fondo Europeo de Desarrollo Regional (FEDER)". The RIS Cohort (CoRIS) is funded by the Instituto de Salud Carlos III through the Red Temática de Investigación Cooperativa en SIDA (RIS C03/173, RD12/0017/0018 and RD16/0002/0006) as part of the Plan Nacional R+D+I and cofinanced by ISCIII-Subdirección General de Evaluacion y e Fondo Europeo de Desarrollo Regional (FEDER).

Conflicts of Interest: The authors declare no conflict of interest.

\section{Appendix A}

Centers and investigators involved in CoRIS:

Executive committee: Santiago Moreno, Julia del Amo, David Dalmau, Maria Luisa Navarro, Maria Isabel González, Jose Luis Blanco, Federico Garcia, Rafael Rubio, Jose Antonio Iribarren, Félix Gutiérrez, Francesc Vidal, Juan Berenguer, Juan González.

Fieldwork, data management and analysis: Julia Del Amo, Inma Jarrín, Belén Alejos, Victoria Hernando, Cristina Moreno, Carlos Iniesta, Luis Miguel Garcia Sousa, Nieves Sanz Perez.

BioBanK HIV: Hospital General Universitario Gregorio Marañón: M Ángeles Muñoz-Fernández, Isabel María García-Merino, Irene Consuegra Fernández, Coral Gómez Rico, Jorge Gallego de la Fuente, Paula Palau Concejo.

\section{Participating centres:}


Hospital General Universitario de Alicante (Alicante): Joaquín Portilla, Esperanza Merino, Sergio Reus, Vicente Boix, Livia Giner, Carmen Gadea, Irene Portilla, María Pampliega, Marcos Díez, Juan Carlos Rodríguez, José Sánchez-Payá.

Hospital Universitario de Canarias (San Cristobal de la Laguna): Juan Luis Gómez， Jehovana Hernández, María Remedios Alemán, María del Mar Alonso, María Inmaculada Hernández, Felicitas Díaz-Flores, Dácil García, Ricardo Pelazas, Ana López Lirola.

Hospital Universitario Central de Asturias (Oviedo): José Sanz Moreno, Alberto Arranz Caso, Cristina Hernández Gutiérrez, María Novella Mena.

Hospital Universitario 12 de Octubre (Madrid): Rafael Rubio, Federico Pulido, Otilia Bisbal, Asunción Hernando, Lourdes Domínguez, David Rial Crestelo, Laura Bermejo, Mireia Santacreu.

Hospital Universitario de Donostia (Donostia-San Sebastián): José Antonio Iribarren, Julio Arrizabalaga, María José Aramburu, Xabier Camino, Francisco Rodríguez-Arrondo, Miguel Ángel von Wichmann, Lidia Pascual Tomé, Miguel Ángel Goenaga, M $M^{a}$ Jesús Bustinduy, Harkaitz Azkune, Maialen Ibarguren, Aitziber Lizardi, Xabier Kortajarena.

Hospital General Universitario De Elche (Elche): Félix Gutiérrez, Mar Masiá, Sergio Padilla, Andrés Navarro, Fernando Montolio, Catalina Robledano, Joan Gregori Colomé, Araceli Adsuar, Rafael Pascual, Marta Fernández, Elena García., José Alberto García, Xavier Barber.

Hospital General Universitario Gregorio Marañón (Madrid): Juan Berenguer, Juan Carlos López Bernaldo de Quirós, Isabel Gutiérrez, Margarita Ramírez, Belén Padilla, Paloma Gijón, Teresa Aldamiz-Echevarría, Francisco Tejerina, Francisco José Parras, Pascual Balsalobre, Cristina Diez, Leire Pérez Latorre.

Hospital Universitari de Tarragona Joan XXIII (Tarragona): Francesc Vidal, Joaquín Peraire, Consuelo Viladés, Sergio Veloso, Montserrat Vargas, Miguel López-Dupla, Montserrat Olona, Anna Rull, Esther Rodríguez-Gallego, Verónica Alba.

Hospital Universitario y Politécnico de La Fe (Valencia): Marta Montero Alonso, José López Aldeguer, Marino Blanes Juliá, María Tasias Pitarch, Iván Castro Hernández, Eva Calabuig Muñoz, Sandra Cuéllar Tovar, Miguel Salavert Lletí, Juan Fernández Navarro.

Hospital Universitario La Paz/IdiPAZ: Juan González-garcia, Francisco Arnalich, José Ramón Arribas, Jose Ignacio Bernardino de la Serna, Juan Miguel Castro, Luis Escosa, Pedro Herranz, Victor Hontañón, Silvia García-Bujalance, Milagros García López-Hortelano, Alicia González-Baeza, Maria Luz Martín-Carbonero, Mario Mayoral, Maria Jose Mellado, Rafael Esteban Micán, Rocio Montejano, María Luisa Montes, Victoria Moreno, Ignacio Pérez-Valero, Berta Rodés, Talia Sainz, Elena Sendagorta, Natalia Stella Alcáriz, Eulalia Valencia.

Hospital San Pedro Centro de Investigación Biomédica de La Rioja (CIBIR) (Logroño): José Ramón Blanco, José Antonio Oteo, Valvanera Ibarra, Luis Metola, Mercedes Sanz, Laura Pérez-Martínez.

Hospital Universitari MutuaTerrassa (Terrasa): David Dalmau, Angels Jaén, Montse Sanmartí, Mireia Cairó, Javier Martinez-Lacasa, Pablo Velli, Roser Font, Mariona Xercavins, Noemí Alonso.

Complejo Hospitalario de Navarra (Pamplona) María Rivero, Jesús Repáraz, María Gracia Ruiz de Alda, María Teresa de León Cano, Beatriz Pierola Ruiz de Galarreta.

Corporació Sanitària Parc Taulí (Sabadell): Ferrán Segura, María José Amengual, Gemma Navarro, Montserrat Sala, Manuel Cervantes, Valentín Pineda, Sonia Calzado, Marta Navarro.

Hospital Universitario de La Princesa (Madrid): Ignacio de los Santos, Jesús Sanz Sanz, Ana Salas Aparicio, Cristina Sarriá Cepeda, Lucio Garcia-Fraile Fraile, Enrique Martín Gayo. 
Hospital Universitario Ramón y Cajal (Madrid): Santiago Moreno, José Luis Casado, Fernando Dronda, Ana Moreno, María Jesús Pérez Elías, Cristina Gómez Ayerbe, Carolina Gutiérrez, Nadia Madrid, Santos del Campo Terrón, Paloma Martí, Uxua Ansa, Sergio Serrano, María Jesús Vivancos.

Hospital General Universitario Reina Sofía (Murcia) Enrique Bernal, Alfredo Cano, Antonia Alcaraz García, Joaquín Bravo Urbieta, Ángeles Muñoz, Maria Jose Alcaraz, Maria del Carmen Villalba.

Hospital Nuevo San Cecilio (Granada): Federico García, José Hernández, Alejandro Peña, Leopoldo Muñoz, Paz Casas, Marta Alvarez, Natalia Chueca, David Vinuesa, Clara Martinez-Montes.

Centro Sanitario Sandoval (Madrid): Jorge Del Romero, Carmen Rodríguez, Teresa Puerta, Juan Carlos Carrió, Mar Vera, Juan Ballesteros, Oskar Ayerdi.

Hospital Universitario Son Espases (Palma de Mallorca): Melchor Riera, María Peñaranda, María Leyes, $\mathrm{M}^{\mathrm{a}}$ Angels Ribas, Antoni A Campins, Carmen Vidal, Francisco Fanjul, Javier Murillas, Francisco Homar.

Hospital Universitario Virgen de la Victoria (Málaga): Jesús Santos, Crisitina Gómez Ayerbe, Isabel Viciana, Rosario Palacios, Carmen María González.

Hospital Universitario Virgen del Rocío (Sevilla): Pompeyo Viciana, Nuria Espinosa, Luis Fernando López-Cortés.

Hospital Universitario de Bellvitge (Hospitalet de Llobregat): Daniel Podzamczer, Elena Ferrer, Arkaitz Imaz, Juan Tiraboschi, Ana Silva, María Saumoy.

Hospital Costa del Sol (Marbella): Julián Olalla, Alfonso del Arco, Javier de la torre, José Luis Prada, José María García de Lomas Guerrero, Javier Pérez Stachowski.

Hospital General Universitario Santa Lucía (Cartagena): Onofre Juan Martínez, Francisco Jesús Vera, Lorena Martínez, Josefina García, Begoña Alcaraz, Amaya Jimeno.

Complejo Hospitalario Universitario a Coruña (Chuac) (A Coruña): Angeles Castro Iglesias, Berta Pernas Souto, Alvaro Mena de Cea.

Hospital Universitario Virgen de la Arrixaca (El Palmar): Carlos Galera, Helena Albendin, Aurora Pérez, Asunción Iborra, Antonio Moreno, Maria Angustias Merlos, Asunción Vidal.

Hospital Universitario Infanta Sofia (San Sebastian de los Reyes): Inés Suárez-García, Eduardo Malmierca, Patricia González-Ruano, Dolores Martín Rodrigo.

Complejo Hospitalario de Jaén (Jaén) Mohamed Omar Mohamed-Balghata, María Amparo Gómez Vidal.

Hospital Clínico San Carlos (Madrid): Vicente Estrada Pérez, Maria Jesus Téllez Molina, Jorge Vergas García, Juncal Pérez-Somarriba Moreno.

Hospital Universitario Fundación Jiménez Díaz (Madrid): Miguel Górgolas, Alfonso Cabello., Beatriz Álvarez., Laura Prieto.

Hospital Universitario Príncipe de Asturias (Alcalá de Henares): José Sanz Moreno, Alberto Arranz Caso, Cristina Hernández Gutiérrez, María Novella Mena.

Hospital Clínico Universitario de Valencia (València): María José Galindo Puerto, Ramón Fernando Vilalta, Ana Ferrer Ribera.

Hospital Reina Sofía (Córdoba): Antonio Rivero Román, Maria Teresa Brieva Herrero, Antonio Rivero Juárez, Pedro López López, Isabel Machuca Sánchez, José Peña Martínez.

Hospital Universitario Severo Ochoa (Leganés): Miguel Cervero Jiménez, Rafael Torres Perea, Juan José Jusdado Ruiz-Capillas. 
Nuestra Señora de Valme: Juan A Pineda.

\section{Appendix B}

\section{Centers involved in Long Term Non-Progressors (LTNP) chort:}

Centro Sanitario Sandoval-Madrid

Hospital 12 de Octubre-Madrid

Hospital Arnau de Vilanova-Lleida

Hospital Asturias

Hospital Bellvitge-Barcelona

Hospital Castellón

Hospital Clínic-Barcelona

Hospital Donostia-San Sebastián

Hospital Elche-Alicante

Hospital Germans Trias i Pujol—Badalona

Hospital Gregorio Marañón-Madrid

Hospital Joan XXIII-Tarragona

Hospital La Fe-Valencia

Hospital La Paz/Carlos III-Madrid

Hospital La Princesa-Madrid

Hospital Navarra-Pamplona

Hospital Parc Taulí- Sabadell

Hospital Ramón y Cajal-Madrid

Hospital San Cecilio-Granada

Hospital San Pedro-Logroño

Hospital Son Dureta-Mallorca

Hospital Virgen del Rocío-Sevilla

\section{References}

1. Munoz, A.; Sabin, C.A.; Phillips, A.N. The incubation period of AIDS. AIDS 1997, 11, S69-S76. [PubMed]

2. Pantaleo, G.; Fauci, A.S. Immunopathogenesis of HIV infection. Ann. Rev. Microbiol. 1996, 50, 825-854. [CrossRef] [PubMed]

3. Gurdasani, D.; Iles, L.; Dillon, D.G.; Young, E.H.; Olson, A.D.; Naranbhai, V.; Fidler, S.; Gkrania-Klotsas, E.; Post, F.A.; Kellam, P.; et al. A systematic review of definitions of extreme phenotypes of HIV control and progression. AIDS 2014, 28, 149-162. [CrossRef] [PubMed]

4. Estes, J.D.; LeGrand, R.; Petrovas, C. Visualizing the immune system: Providing key insights into HIV/SIV infections. Front. Immunol. 2018, 9, 423. [CrossRef] [PubMed]

5. Biasin, M.; De Luca, M.; Gnudi, F.; Clerici, M. The genetic basis of resistance to HIV infection and disease progression. Expert Rev. Clin. Immunol. 2013, 9, 319-334. [CrossRef] [PubMed]

6. Autier, P.; Boniol, M.; Pizot, C.; Mullie, P. Vitamin D status and ill health: A systematic review. Lancet Diabetes Endocrinol. 2014, 2, 76-89. [CrossRef]

7. Jimenez-Sousa, M.A.; Martinez, I.; Medrano, L.M.; Fernandez-Rodriguez, A.; Resino, S. Vitamin D in human immunodeficiency virus infection: Influence on immunity and disease. Front. Immunol. 2018, 9, 458. [CrossRef] [PubMed]

8. $\quad$ Lucas, R.M.; Gorman, S.; Geldenhuys, S.; Hart, P.H. Vitamin D and immunity. F1000Prime Rep. $2014,6,118$. [CrossRef] [PubMed]

9. Mansueto, P.; Seidita, A.; Vitale, G.; Gangemi, S.; Iaria, C.; Cascio, A. Vitamin D deficiency in HIV infection: Not only a bone disorder. BioMed Res. Int. 2015, 2015, 735615. [CrossRef] [PubMed]

10. Gois, P.H.F.; Ferreira, D.; Olenski, S.; Seguro, A.C. Vitamin D and infectious diseases: Simple bystander or contributing factor? Nutrients 2017, 9, 651. [CrossRef] [PubMed] 
11. Hossein-nezhad, A.; Holick, M.F. Vitamin D for health: A global perspective. Mayo Clin. Proc. 2013, 88, 720-755. [CrossRef] [PubMed]

12. Fang, Y.; van Meurs, J.B.; d'Alesio, A.; Jhamai, M.; Zhao, H.; Rivadeneira, F.; Hofman, A.; van Leeuwen, J.P.; Jehan, F.; Pols, H.A.; et al. Promoter and 3'-untranslated-region haplotypes in the vitamin D receptor gene predispose to osteoporotic fracture: The rotterdam study. Am. J. Hum. Genet. 2005, 77, 807-823. [CrossRef] [PubMed]

13. Nejentsev, S.; Godfrey, L.; Snook, H.; Rance, H.; Nutland, S.; Walker, N.M.; Lam, A.C.; Guja, C.; Ionescu-Tirgoviste, C.; Undlien, D.E.; et al. Comparative high-resolution analysis of linkage disequilibrium and tag single nucleotide polymorphisms between populations in the vitamin D receptor gene. Hum. Mol. Genet. 2004, 13, 1633-1639. [CrossRef] [PubMed]

14. Jolliffe, D.A.; Walton, R.T.; Griffiths, C.J.; Martineau, A.R. Single nucleotide polymorphisms in the vitamin D pathway associating with circulating concentrations of vitamin D metabolites and non-skeletal health outcomes: Review of genetic association studies. J. Steroid Biochem. Mol. Biol. 2016, 164, 18-29. [CrossRef] [PubMed]

15. Barber, Y.; Rubio, C.; Fernandez, E.; Rubio, M.; Fibla, J. Host genetic background at CCR5 chemokine receptor and vitamin D receptor loci and human immunodeficiency virus (HIV) type 1 disease progression among HIV-seropositive injection drug users. J. Infect. Dis. 2001, 184, 1279-1288. [CrossRef] [PubMed]

16. Laplana, M.; Sanchez-de-la-Torre, M.; Puig, T.; Caruz, A.; Fibla, J. Vitamin-D pathway genes and HIV-1 disease progression in injection drug users. Gene 2014, 545, 163-169. [CrossRef] [PubMed]

17. Nieto, G.; Barber, Y.; Rubio, M.C.; Rubio, M.; Fibla, J. Association between AIDS disease progression rates and the Fok-I polymorphism of the VDR gene in a cohort of HIV-1 seropositive patients. J. Steroid Biochem. Mol. Biol. 2004, 89-90, 199-207. [CrossRef] [PubMed]

18. Torres, C.; Sanchez de la Torre, M.; Garcia-Moruja, C.; Carrero, A.J.; Trujillo Mdel, M.; Fibla, J.; Caruz, A. Immunophenotype of vitamin D receptor polymorphism associated to risk of HIV-1 infection and rate of disease progression. Curr. HIV Res. 2010, 8, 487-492. [CrossRef] [PubMed]

19. Garcia-Merino, I.; de Las Cuevas, N.; Jimenez, J.L.; Gallego, J.; Gomez, C.; Prieto, C.; Serramia, M.J.; Lorente, R.; Munoz-Fernandez, M.A. The Spanish HIV BioBank: A model of cooperative HIV research. Retrovirology 2009, 6, 27. [CrossRef] [PubMed]

20. Sobrino-Vegas, P.; Gutierrez, F.; Berenguer, J.; Labarga, P.; Garcia, F.; Alejos-Ferreras, B.; Munoz, M.A.; Moreno, S.; del Amo, J. The Cohort of the Spanish HIV Research Network (CoRIS) and its associated biobank; organizational issues, main findings and losses to follow-up. Enferm. Infec. Microbiol. Clin. 2011, 29, 645-653. [CrossRef] [PubMed]

21. Guzman-Fulgencio, M.; Jimenez, J.L.; Garcia-Alvarez, M.; Bellon, J.M.; Fernandez-Rodriguez, A.; Campos, Y.; Rodriguez, C.; Gonzalez-Garcia, J.; Riera, M.; Viciana, P.; et al. Mitochondrial haplogroups are associated with clinical pattern of AIDS progression in HIV-infected patients. J. Acquir. Immune Defic. Syndr. 2013, 63, 178-183. [CrossRef] [PubMed]

22. Guzman-Fulgencio, M.; Jimenez, J.L.; Jimenez-Sousa, M.A.; Bellon, J.M.; Garcia-Alvarez, M.; Soriano, V.; Gijon-Vidaurreta, P.; Bernal-Morell, E.; Viciana, P.; Munoz-Fernandez, M.A.; et al. ACSM4 polymorphisms are associated with rapid AIDS progression in HIV-infected patients. J. Acquir. Immune Defic. Syndr. 2014, 65, 27-32. [CrossRef] [PubMed]

23. Alagarasu, K.; Selvaraj, P.; Swaminathan, S.; Narendran, G.; Narayanan, P.R. $5^{\prime}$ regulatory and $3^{\prime}$ untranslated region polymorphisms of vitamin D receptor gene in south Indian HIV and HIV-TB patients. J. Clin. Immunol. 2009, 29, 196-204. [CrossRef] [PubMed]

24. De la Torre, M.S.; Torres, C.; Nieto, G.; Vergara, S.; Carrero, A.J.; Macias, J.; Pineda, J.A.; Caruz, A.; Fibla, J. Vitamin D receptor gene haplotypes and susceptibility to HIV-1 infection in injection drug users. J. Infect. Dis. 2008, 197, 405-410. [CrossRef] [PubMed]

25. Aguilar-Jimenez, W.; Villegas-Ospina, S.; Gonzalez, S.; Zapata, W.; Saulle, I.; Garziano, M.; Biasin, M.; Clerici, M.; Rugeles, M.T. Precursor forms of vitamin D reduce HIV-1 infection in vitro. J. Acquir. Immune Defic. Syndr. 2016, 73, 497-506. [CrossRef] [PubMed]

26. Nunnari, G.; Fagone, P.; Lazzara, F.; Longo, A.; Cambria, D.; Di Stefano, G.; Palumbo, M.; Malaguarnera, L.; Di Rosa, M. Vitamin D3 inhibits TNF $\alpha$-induced latent HIV reactivation in J-LAT cells. Mol. Cell. Biochem. 2016, 418, 49-57. [CrossRef] [PubMed] 
27. Mendes, M.M.; Darling, A.L.; Hart, K.H.; Morse, S.; Murphy, R.J.; Lanham-New, S.A. Impact of high latitude, urban living and ethnicity on 25-hydroxyvitamin D status: A need for multidisciplinary action? J. Steroid Biochem. Mol. Biol. 2019. [CrossRef] [PubMed]

28. Gross, C.; Eccleshall, T.R.; Malloy, P.J.; Villa, M.L.; Marcus, R.; Feldman, D. The presence of a polymorphism at the translation initiation site of the vitamin $\mathrm{D}$ receptor gene is associated with low bone mineral density in postmenopausal Mexican-American women. J. Bone Min. Res. 1996, 11, 1850-1855. [CrossRef] [PubMed]

29. Laplana, M.; Royo, J.L.; Fibla, J. Vitamin D Receptor polymorphisms and risk of enveloped virus infection: A meta-analysis. Gene 2018, 678, 384-394. [CrossRef] [PubMed]

30. Ogunkolade, B.W.; Boucher, B.J.; Prahl, J.M.; Bustin, S.A.; Burrin, J.M.; Noonan, K.; North, B.V.; Mannan, N.; McDermott, M.F.; DeLuca, H.F.; et al. Vitamin D receptor (VDR) mRNA and VDR protein levels in relation to vitamin D status, insulin secretory capacity, and VDR genotype in Bangladeshi Asians. Diabetes 2002, 51, 2294-2300. [CrossRef] [PubMed]

31. Kholghi Oskooei, V.; Geranpayeh, L.; Omrani, M.D.; Ghafouri-Fard, S. Assessment of functional variants and expression of long noncoding RNAs in vitamin D receptor signaling in breast cancer. Cancer Manag. Res. 2018, 10, 3451-3462. [CrossRef] [PubMed]

32. Moran-Auth, Y.; Penna-Martinez, M.; Shoghi, F.; Ramos-Lopez, E.; Badenhoop, K. Vitamin D status and gene transcription in immune cells. J. Steroid Biochem. Mol. Biol. 2013, 136, 83-85. [CrossRef] [PubMed]

33. Vanessa, O.; Asani, F.F.; Jeffery, T.J.; Saccone, D.S.; Bornman, L. Vitamin D receptor gene expression and function in a south African population: Ethnicity, vitamin D and FokI. PLoS ONE 2013, 8, e67663.

(C) 2019 by the authors. Licensee MDPI, Basel, Switzerland. This article is an open access article distributed under the terms and conditions of the Creative Commons Attribution (CC BY) license (http://creativecommons.org/licenses/by/4.0/). 